\title{
Knowledge Expert System in Medical Science
}

\author{
Asad, Saru Dhi, Madhurima Hooda
}

\begin{abstract}
Today's doctors need decision making which helps to enable them to adapt to the administration of expanding measures of medicinal data (records, inquire about advances, new medications), settle on fitting decisions and even to substitute in an expert's nonattendance. Such guides exist as medicinal expert system, which are mind boggling PC programs that copy clinical thinking.

The paper introduces the expert system with its utilization in medical science. Also, its further deals with literature and history of the expert system along with the problem faced. The paper also contains the method and algorithm used for diagnosing diseases in human being and recommending the best cure i.e prescribing appropriate medicine with least error using RETE algorithm. The RETE algorithm is an effectively sorted out example coordinating calculation for executing creation rule frameworks, used to figure out which of the generation guidelines should work dependent on its information store. It introduces how it can be utilized to enhance the proficiency of expert system proposal.
\end{abstract}

Keyword: Expert System, Diseases diagnosis, Rete Algorithm, Medical Science.

\section{INTRODUCTION}

$\mathrm{M}$ aster framework (ES) are use of modernized reasoning (AI), \& was made by this society in the middle of 1960s. The essential thought behind Expert framework is just that twisted, which is the huge cluster of assignment express information, is moved from a human to a PC. This learning is then verified in the $\mathrm{PC}$ and clients call upon the PC for express heading as required. The $\mathrm{PC}$ can reach at an end. An ace structure is basically a PC program i.e wanted to keep the amassed information of one or particular zone aces .By then like a human ace, it explains and clarifies, if essential, the explanation for the bearing [1].

Applying data innovation or man-made reasoning in social insurance is vital in giving quick and proficient administrations to customers and adequacy of the medicinal services framework. Human services administrations give data of the conclusion and persistent checking of patient to procure quick reaction and spare lives if there

should be an occurrence of basic conditions. Master frameworks in human services are significant on giving right data for analysis and giving prompt medicinal

Revised Manuscript Received on November 22, 2019.

* Correspondence Author

Mr Mohammad Asad, B.Tech in Information Technology from Amity School of Engineering \& Technology, Amity University, Noida,

Saru Dhir, Software Engineering, Agile Development, Software Testing, Cyber crime.

Madhurima Hooda, Assistant Professor in the Discipline of Information Technology at Amity School of Engineering and Technology, Amity University, Uttar Pradesh, Noida, India administrations. Ebb and flow investigate in choice emotionally supportive network (DSS) utilizes multiagent for the master frameworks [2]. Algorithms that are precise in arranging sicknesses are utilized for therapeutic determination. Neural system is a typical utilized method $[4,3]$. Fruitful application models demonstrate that neural analytic frameworks are superior to human diagnostic capabilities. In addition, neural system is utilized to break down medicinal pictures [5],[6]].

The end client gives input data by choosing one or numerous alternatives from rundown or by entering information. Contingent upon that information, program check learning base, recreates information and takes decision. [7]

An expert system is separated into two subcategories: Knowledge base and the interference engine. The learning base speaks to realities and guidelines. Knowledge base can likewise incorporate clarification and troubleshooting abilities. The second i.e. the interference engine applies the standards to the well-established certainties to find new actualities. [8]

\section{BACKGROUND}

Expert system were presented by the Stanford Heuristic Programming Project around 1965[1] driven by Edward Feigenbaum, which is at times named the "father of expert system"; other donors were Randall Davis and Bruce Buchanan. The Stanford scientists attempted to distinguish areas where mastery was very esteemed and perplexing, for example, diagnosing irresistible ailments (Mycin) and recognizing obscure natural particles (Dendral). The possibility that "clever frameworks get their capacity from the information they have as opposed to from the particular formalisms and induction plans they use"[9]- as Feigenbaum said - was a time noteworthy advance forward , since previous research been centered around heuristic computational strategies, coming full circle in endeavors to grow exceptionally universally useful issue solvers (majorly the work of Allen Newell and Herbert Simon). [10] It turned into a portion of the primary fruitful types of Artificial intelligence software.

Work on this expert system was likewise dynamic in France. Upside of master framework shells was, they were to some degree simpler for non-programmers to utilize. The benefit of Prolog conditions was that they weren't centered distinctly around if-else rules; Prolog situations gave a greatly improved acknowledgment of a total first request rationale environment [11],[12].

During 1980s, knowledge-based system multiplied. Colleges offered master framework courses and $66 \%$ of the Fortune half a thousand organizations connected the innovation in day by day business activities [13]. Interest was universal with the Fifth Generation 
Computer Systems venture in Japan and in Europe expanded research financing

To achieve accomplishments of obvious insight, a specialist framework depends on two segments: an information base and a deduction motor. An information base is a composed gathering of realities about the framework's space. A derivation motor deciphers and assesses the realities in the information base to give an answer. Run of the mill errands for master frameworks include characterization, conclusion, checking, structure, booking, and getting ready for undertakings [14] [15].

Certainties for a learning base must be gained from human specialists through meetings and perceptions. This information is then normally spoken to as "if-then" rules (generation rules): "On the off chance that some condition is valid, at that point the accompanying deduction can be made (or some move made)." The learning base of a noteworthy master framework incorporates many standards [16]. A likelihood factor is regularly joined to the finish of every generation rule and to a definitive proposal, on the grounds that the determination isn't a sureness. For instance, a framework for the finding of eye sicknesses may show, in view of data provided to it, a 90 percent likelihood that an individual has glaucoma, and it may likewise list ends with lower probabilities. A specialist framework may show the grouping of guidelines through which it touched base at its decision; following this stream causes the client to evaluate the validity of its proposal and is valuable as a learning device for understudies.

Human specialists every now and again utilize heuristic standards, or "rules of thumb," notwithstanding basic generation rules, for example, those gathered from building handbooks. Subsequently, a credit administrator may realize that a candidate with a poor financial record, yet a perfect record since obtaining another activity, may really be a decent credit hazard. Expert system has fused such heuristic principles and progressively can gain as a matter of fact. It remains helps to, as opposed to trades for, human specialists.

\section{PROBLEM FACED IN EXPERT SYSTEM}

On the specialized side, there is the issue regarding the size of the database and utilizing it productively. On the off chance that the framework comprises of a few thousand principles, it takes an exceptionally ground-breaking control program to create any determinations in a sensible measure of time. On the off chance that the framework additionally has an enormous amount of data in the working memory, this will likewise back things off except if you have a generally excellent ordering and search framework [3][4].

A second issue that originates from an enormous database is that as the quantity of principles expands the contention set additionally turns out to be huge so a decent clash settling calculation is required if the framework is to be used

Another issue that shows up is that of obligation. Take, for instance, a framework utilized by a specialist that is intended to regulate medications to patients as per their needs and that it should initially figure out what's up with them, particularly like the endorsing work of a GP. On the off chance that the framework makes somebody take the off-base drug and the individual is hurt, who is lawfully capable? Some would state the wellbeing specialist who enabled the specialist to utilize the framework, others would state the specialist, others the providers of the Expert System. An issue is delivered that isn't at all a unimportant one. Consider the ramifications of utilizing Expert Systems in different situations. [2]

A progressively clear issue is that of social affair the standards. Human specialists are costly and are not incredibly prone to need to plunk down and work out countless principles with respect to how they arrive at their decisions. More to the point, they will most likely be unable to. Although they will as a rule pursue an intelligent way to their decisions, placing these into a lot of IF ... At that point standards may really be extremely troublesome and perhaps unthinkable.

It is very conceivable that numerous human specialists, however beginning off in their callings with a lot of standards, figure out how to carry out their responsibility through experiential information and 'simply know' what the right arrangement is. Again they may have pursued a sensible way, yet rationally they may have 'avoided a few stages' en route to arrive. An Expert System can't do this and has to know the standards in all respects unmistakably.

What might be a path round this issue is to empower Expert Systems to learn as they go, beginning off with fewer guidelines yet enabled to derive new standards from what they know and what they 'experience'. This leads us in all respects pleasantly into the field of Computer Learning.

Regardless of the expanding utilization of expert system in prescription, it ought to be focused on that the improvement of such frameworks for restorative applications needs to outperform some essential deterrents, for example, Medical assignments are troublesome as a result of contrasts between patients and the vulnerability of the accessible clinical information.

- The scope of worthy blunders is little a direct result of moral concerns and misbehavior dangers.

- Funding for capital costs is hard to find [12].

\section{METHODOLOGY AND PROPOSED WORK}

\section{A. Rete algorithm}

Rete algorithm is a data matching algorithm developed by Doctor Charles Forgy of Carnegie Mellon University. Basically, RETE is a Latin word for 'net'. It is a remarkable algorithm for facts matching and data's matching, with the certain rules.

The RETE system is a direct non-cyclic chart that comprises of hubs speaking to designs in the states of the standards. The hubs carry on like channels; they test the approaching token and send just those that have finished the test. The RETE system comprises of two parts: alpha system and beta system. Alpha system comprises of hubs known as alpha hubs. Every alpha hub comprises of one input that characterizes intra-components. Beta hubs are segments of Beta system where two information sources are taken from every hub in order to characterize between component conditions.

Various symptoms leads to certain hazardous diseases, these are the fundamental part of the system. It is done as the representation of if-else rules in the system. Few of them are given below. 


\section{B. For instance:}

Case 1:

if((criteria[0].equals(“nasal conjestion”) \&\& criteria[1].equals("common cold")) return "benadryl";

Case 2:

if(criteria[0].equals("vomiting") \&\&

criteria[1]. Equals("migraine")) return "sumatriptan";

Case 3:

if(criteria[0].equals(“dizziness") \&\&

criteria[1].equals("hypertension")) return "norvasc";

Case 4:

if(criteria[0].equals("shortn ess of breadth") \&\& criteria[1].equals(“asthma")) return " ";

Case 5 :

if(criteria[0].equals ("sleeplessness")

$\& \&$ criteria[1].equals("insomnia")) return "ambien ";

(0) -deals with the symptom (1)- deals with disease

Table I. Diseases,Symptoms and medicine.

\begin{tabular}{|c|c|c|}
\hline $\begin{array}{l}\text { Common } \\
\text { cold }\end{array}$ & $\begin{array}{c}\text { Nasal conjestion } \\
\text { General malaise } \\
\text { Watery nasal } \\
\text { rhinorrhea }\end{array}$ & $\begin{array}{l}\text { Benadryl } \\
\text { Vicks } \\
\text { Nyquil D } \\
\text { old and Flu } \\
\text { Night time } \\
\text { relief. }\end{array}$ \\
\hline Migraine & $\begin{array}{c}\text { Vomiting } \\
\text { Nausea } \\
\text { Sensitive to light }\end{array}$ & $\begin{array}{c}\text { Sumatripta } \\
\mathrm{n} \\
\text { Imitrex } \\
\text { Maxalt } \\
\text { Zomig }\end{array}$ \\
\hline Asthma & $\begin{array}{c}\text { Shortness of breadth } \\
\text { Chest tightening } \\
\text { Coughing }\end{array}$ & $\begin{array}{c}\text { Dulera } \\
\text { Antrovent } \\
\text { Singulair }\end{array}$ \\
\hline Constipation & $\begin{array}{l}\text { No bowel movement } \\
\text { for more than } 3 \text { days } \\
\text { Pain during the } \\
\text { passage of bowel } \\
\text { movement }\end{array}$ & $\begin{array}{c}\text { Colace } \\
\text { Miralax } \\
\text { Docusate }\end{array}$ \\
\hline Insomnia & $\begin{array}{c}\text { Abnormal } \\
\text { wakefulness } \\
\text { Sleeplessness }\end{array}$ & $\begin{array}{c}\text { Trazodone } \\
\text { Ambien } \\
\text { Lunesta }\end{array}$ \\
\hline
\end{tabular}

Match capacity of this calculation is written below. Components in the current memory is spoken to with arrayParameter. Components of arrayParameter may contain negative \& positive signs. "+"sign demonstrates the component isn't coordinated with some LHS of guideline and it must be coordinated in principle base with standards. A negative mark or - shows that the memory component is coordinated with at least one standard and can't be utilized later for coordinating with guidelines.

Match(parameterArray)

do

If(+(parameterArray.Element)equals

RulesLHS)

Then

parameterElement=-

( parameterArray.MatchedElement)

If(All parameterArray.Elements Begins

with - )

Then

Return RHS

$\mathrm{Fi}$

parameterArray.Add(+(RHS))

Match(parameterArray)

$\mathrm{Fi}$

Done

\section{V.GENERAL DESCRIPTION FOR ESTIMATING THE BEST MEDICINE SYSTEM}

Rete Algorithm utilizes data to improve productivity ('rete' is Latin for 'net'). To begin with, the underlying clash set is created through the coordinating the algorithm by associating the system for all condition parts. From that point onward, just the changed components in working memory are nourished into the system to recognize the adjustments in the contention set [11].

The above ideas and prescience are combined into a solitary brought together as an algorithm

Information: Diseases data, Medicine data, Disease for doctor diagnosis.

Yield: Medicines Prescribed

Start:

- Enter patient's Symptoms.

- For each Diseases That are for doctor diagnosisDN)

- Find Diseases Symptoms 


\section{Knowledge Expert System in Medical Science}

- Then find Similar Symptoms between symptoms of the patient and diseases symptom and put it on new table or array which is of similar symptoms.

- (If Similar symptoms is found in Medicine data Then Medicine ( $) \rightarrow$ Count +1 ) i.e. Compare Similar symptoms with Medicine Data for diseases for doctor diagnosis

- Sort Medicines Prescribed ()

- Select the minimum Error Percentage

- If the estimation of medicines prescribed is equal, at that point select the high priority from medicine data.

\section{RESULT}

The results likewise incorporate Rete Algorithm for Prescription. The outcomes are composed in form medicine for illnesses. Brief portrayals and the conclusion were given by the specialists and furthermore by the proposed framework-Estimation Medicine for Diseases (EMD) that offers choosing the best prescription for a given ailment.

The proposed framework manages numerous diseases.Expert system investigates the connected encouraged information. Each put away table is used to test distinctive infection cases. The framework was arranged more than five classes speaking to the chose heart maladies.

The system has been tried by entering manifestations and medicinal history of every patient. Information are gone into the constructed structure, at that point counts of the likelihood of events of the illness for every patient are made. This outcome is the probability of ailment for every patient alongside the chose drug. The specialists can pick two of the top up conceivable outcomes of these drugs (for example the higher need among them).

\section{CONCLUSION}

This paper exhibits an overview of past paper for similar topic with some favorable position \& disservices. Additionally, this paper gives unique accentuation of master framework in the stream of restorative science. In this paper, a methodology dependent on Rete Algorithm is utilized where the best-picked prescription through the framework is recommended. The exactness is acquired on the grounds that the standards of selecting drugs by a specialist for a given patient depend on two variables. The primary factor is the indications experienced by the patient alongside his medicinal history, while the subsequent one is the synthetic connections that occur inside the patient's body. This system relies upon the principal factor in which the choice of drug is made to maintain a strategic distance from the meddling with different medicaments for a specific infection.

\section{REFERENCES}

[1] BalramKishan Et AI,“ A Review Of Development And Applications Of Expert System, International Journal Of Advanced Research In Computer Science And Software Engineering Volume 2", Issue 10 ,(2012)

[2] Foster D., et al. "A Survey of Agent-Based Intelligent Decision Support Systems to Support Clinical Management and Research", 1st Intl. Workshop on Multi-Agent Systems for Medicine, Computational Biology, and Bioinformatics, Utrecht, Netherlands, (2005)

[3] Brause, R., "Medical Analysis and Diagnosis by Neural Networks", Medical Data Analysis, Springer-Verlag, (2001)

[4] Joo, S., Moon, W. K., and Kim, H. C., "Computer-Aide d Diagnosis of Solid Breast Nodules on Ultrasound with Digital Image Processing

and Artificial Neural Networ k" Engineering in Medicine and Biology Society, Vol. 1, (2004)

[5] Giger, M. L., "Computer-Aided Diagnosis of Breast Lesions in Medical Images" IEEE Computational Science a nd Engineering, Vol. 2, No. 5, (2000)

[6] Verma, B.; Zakos, J., "A Computer-aided Diagnosis System for Digital Mammograms based on FuzzyNeural and Feature Extraction Techniques" IEEE Transactions on Fig. 12 Global load monitoring updating the loads from each objects Information Technology in Biomedicine, Vol. 5, No. 1, (2000)

[7] J. S. Jadhav Et Al(2013)," Research Aspect Of Expert System Of Indian Judiciary Of Crime Against Women, The International Journal Of Engineering And Science (IJES)", Volume 2 Issue 7

[8] Nwigbo Stella and Agbo Okechuku Chuks, "Knowledge-based systems collect the small fragments of human know-how into a knowledge-base which is used to reason through a problem, using the knowledge that is appropriated"

[9] Edward Feigenbaum," "The Art of Artificial Intelligence 1. Themes and Case Studies of Knowledge Engineering",Aug 1977

[10] Hayes-Roth, Frederick; Waterman, Donald; Lenat, Douglas. "Building Expert Systems". Addison-Wesley , 1983

[11] George F. Luger and William A. Stubblefield, Benjamin/Cummings Publishers, "Rule Based Expert System Shell: example of code using the Prolog rule based expert system shell"

[12] A. Michiels, Université de Liège, Belgique: "PROLOG, the first declarative language"

[13] Durkin, "Expert Systems: Catalog of Applications. Intelligent Computer Systems, Inc., Akron", (1993)

[14] Shradha Sapra, Madhurima Hooda, Anshul Chhabra, Saru Dhir, "Smart Med-Minder", Indian Journal of Public Health Research \& Development, November 2018, Vol.9, No. 11, page 661.

[15] Akriti Sood, Madhurima Hooda, Saru Dhir and Madhulika Bhatia, "An Initiative to Identify Depression using Sentiment Analysis: A Machine Learning Approach", Indian Journal of Science and Technology, Vol 11(4), ISSN (Online) : 0974-5645, Jan. 2018.

[16] Shradha, Madhurima and Saru Dhir, "IoT For Healthcare: Challenges and Future Prospects", Presented in 5th International Conference on "Computing for Sustainable Global Development" (INDIACom 2018) on 14th - 16th March, 2018.

\section{AUTHORS PROFILE}

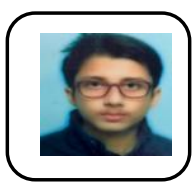

Mr Mohammad Asad is pursuing B.Tech in Information Technology from Amity School of Engineering \& Technology, Amity University, Noida, Batch (2018-22). His area of interests are Machine Learning, Artificial Intelligence, Deep Learning ,Web development, Cloud Computing and Data Science. He has attended various workshops and seminars at national level.

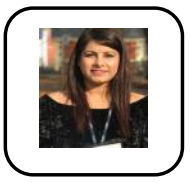

Dr. Madhurima Hooda is currently working as an Assistant Professor in the Discipline of Information Technology at Amity School of Engineering and Technology, Amity University, Uttar Pradesh, Noida, India. She has approximately 14 years of Teaching and research experience. She has published many research papers in national and international journals and conferences of repute. She has published a book titled "Computer Networks" with Laxmi publications and contributed as an editor in global edition of the book "Absolute Java", Pearson Education. Her area of research is video object tracking, software testing, IoT, AJAX Applications and Machine learning. Her M.Tech work has been published as a book titled "Video Object Tracking" by LAP LAMBERT Academic Publishing GmbH \& Co. KG, Germany. She has currently three patents and two copyrights on her name. She is an editor of Journal of Information Processing Systems (Scopus indexed). She is also a member of several professional bodies IETE, IFERP, IOAP and many more.

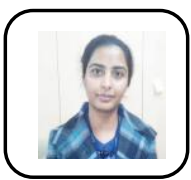

Dr. Saru Dhir has done her Ph.D in CSE, M.Tech in CS and M.Sc. She has more than 14 years of experience in teaching and research. Her research areas are: Software Engineering, Agile Development, Software Testing, Cyber crime. She has published many research papers in national and international journals and conferences of repute. She has completed Microsoft technology associate certification in DBA, C\#, Networking and visual basic. 